\title{
Papers
}

\section{Economic evaluation of nurse led intermediate care versus standard care for post-acute medical patients: cost minimisation analysis of data from a randomised controlled trial}

\author{
Bronagh Walsh, Andrea Steiner, Ruth M Pickering, Jilly Ward-Basu
}

\begin{abstract}
Objective To undertake an economic evaluation of nurse led intermediate care compared with standard hospital care for post-acute medical patients.

Design Cost minimisation analysis from an NHS perspective, comprising secondary care, primary care, and community care, using data from a pragmatic randomised controlled trial.

Setting Nurse led unit and acute general medical wards in large, urban, UK teaching hospital.

Participants 238 patients.

Outcome measure Costs to acute hospital trusts and to the NHS over six months.

Results On an intention to treat basis, nurse led care was associated with higher costs during the initial admission period (nurse led care $£ 7892$ (\$14 970; €11 503), standard care $£ 4810$, difference $£ 3082$ (95\% confidence interval £1161 to £5002)). During the readmission period, costs were similar (nurse led care $£ 1444$, standard care $£ 1879$, difference $-£ 435$, - £1406 to $£ 536$ ). Total costs at six months were significantly higher (nurse led care $£ 10$ 529, standard care $£ 7819$, difference $£ 2710$, £518 to $£ 4903)$. Sensitivity analyses suggested that the trend for nurse led care to be more expensive was maintained even with substantial cost reductions, although differences were no longer significant.

Conclusion Acute hospitals may not be cost effective settings for nurse led intermediate care. Both inpatient and total costs were significantly higher for nurse led care than for standard care of post-acute medical patients, suggesting that this model of care should not be pursued unless clinical or organisational benefits justify the increased investment.
\end{abstract}

\section{Introduction}

As demand for services provided by acute hospitals continues to rise, attention has focused on prevention of inappropriate or avoidable hospital stays. ${ }^{1}$ Intermediate care comprises a range of services at the interface between secondary care and primary care. ${ }^{2}$ These services are recognised as having potential to reduce avoidable admission to hospital and to improve the transition from hospital to home by supporting timely, appropriate discharge. $^{2-4}$ Several models of intermediate care are in operation, and yet no consensus exists on the most effective or cost effective approaches. One increasingly popular model that has been relatively well researched is nurse led care of inpatients recovering from acute illness. Early evaluations suggested that this model of care, when compared with standard care in acute hospital settings, could improve patient outcomes and reduce costs. ${ }^{56}$ More recent, rigorous evaluations, however, found no improvement in patient outcomes with this model of care; rather they consistently report increased hospital stay compared with standard care..$^{7-9}$ This raises important questions about the cost effectiveness of nurse led inpatient care at a time when this type of care is being more widely implemented. ${ }^{9}$ Proponents of the model may presume that the altered working environment and staffing patterns will reduce costs despite an increase in length of stay, and there is therefore a need to clarify the cost implications of introducing this model of care in acute settings. We carried out an economic evaluation, using cost minimisation analysis, based on a pragmatic randomised controlled trial ${ }^{7}$ comparing inpatient care in a nurse led unit with standard care of medical patients on an acute ward. The evaluation was designed to take an NHS perspective, including secondary care, primary care, and community care.

\section{Methods and participants}

We undertook an economic evaluation of nurse led intermediate care of medical patients recovering from acute illness based on a randomised controlled trial. ${ }^{7}$ The trial used a randomised consent design and was intended to detect moderate differences in length of stay, physical functioning, and destination after discharge. In total, 240 medical patients were recruited and allocated to nurse led inpatient care or standard care, although two refused consent for data collection for economic evaluation. Overall, 238 patients were followed up for six months. No differences were observed in any outcomes other than length of stay, which was significantly longer in the nurse led group. ${ }^{7}$ We compared inpatient costs and costs after discharge from randomisation to six months using an intention to treat analysis. Costs are in pounds sterling and were calculated for the financial year 1998-9. Costs were not discounted, owing to the short study period. We made cost valuations after literature review and after interviewing staff in relevant trust directorates and accounting departments. When attributed cost data could not be isolated, we obtained aggregated cost estimates from the trust.

\section{Data collection}

To allow time for accurate information on service use to have been recorded in trust databases, we collected data on utilisation retrospectively. The unit of analysis for length of stay was one day. We abstracted data on use of hospital resources (by location and by day) from the hospital's Patient Administration System database. Data on use of physiotherapy and radiology were col- 
lected directly from the databases within each of these departments. We identified participants by their hospital patient registration number, and accuracy of identification was confirmed by checking date of birth, name, and address. General practice staff collected the primary care data at the end of the six month study period using a standardised data extraction form. Interviews with patients provided information on changes in residence, specifically to an institutional setting, with dates verified by the care home. We selected a random sample of $10 \%$ of the study cohort to test for inter-rater reliability, which showed $100 \%$ agreement between two researchers for all data sources.

\section{Cost specifications}

Most cost estimates for the hospital came from the centralised contracts and costing department. Estimates of costs per occupied bed day by ward came from the relevant directorate finance department. The estimates comprise direct staff costs (calculated for each ward) and indirect costs, including use of pathology, occupational therapy, clerical support, and hotel and laundry services (apportioned between wards in a directorate). The estimates exclude outpatient attendances, for which we used as a source of valuation Unit Costs of Community Care. ${ }^{10}$

We measured hospital stay by ward for two time periods: the admission period (period 1), which extended from randomisation to first discharge home to any destination other than a hospital, and the readmissions period (period 2), which included all subsequent days spent in hospital during the six month study period. From the specialty database, we identified physiotherapy input for both time periods. We measured contacts by the day, and we assumed that they lasted 20 minutes unless otherwise specified in the records. Radiology input was also established on an individual patient basis for both periods. Other contacts with therapy services, hospital doctor and nurse time, and inputs from pathology were embedded in trust estimates of cost per occupied bed day in each ward. (Cost per occupied bed day for the nurse led unit was lower than for other specialist wards, but higher than that for general acute medical wards.) Several factors contributed to the higher average costs for the nurse led unit: the small size of the unit (10 beds compared with 20-30 on general wards); higher than expected costs for nursing staff owing to employment on average of a higher grade of nurse than the medical wards; and a location distant from the main hospital that complicated, and possibly artificially inflated, the attribution of overhead costs.

Episodes of short term care, such as attendances at outpatient clinics, day surgery, and visits to the accident and emergency department, were measured by attendance or procedure. Other NHS resources included community hospitals (both periods), contacts with surgery based general practitioners and community nurses, home visits by general practitioners and community nurses, and telephone contacts with community nurses and general practitioners. Contacts with general practitioners in surgery were assumed to last 10 minutes unless otherwise indicated. Other contacts and days spent in new institutional care were costed according to units provided in Unit Costs of Community Care (table 1). ${ }^{10}$

\section{Output specifications}

We found no significant differences in the primary outcomes of the randomised controlled trial other than length of stay. ${ }^{7}$ In that analysis of effectiveness, hospital days were taken as an outcome, whereas in the economic analysis here, hospital days are treated as an input and therefore no output specifications are required.
Table 1 Costs and data sources for resources in hospital and community settings

\begin{tabular}{|c|c|c|}
\hline Resource & Data source & Unit cost $(£)$ \\
\hline General medical ward* & Acute trust & 146.19 \\
\hline Nurse led unit* & Acute trust & 250.68 \\
\hline Other hospital wards* & Acute trust & 387.00 \\
\hline $\begin{array}{l}\text { Accident and emergency } \\
\text { department per visit }\end{array}$ & Acute trust & 53.00 \\
\hline \multicolumn{3}{|l|}{ Community hospital: } \\
\hline Consultant led & Community trust & 136.15 \\
\hline General practitioner led & Community trust & 100.50 \\
\hline $\begin{array}{l}\text { General practitioner led } \\
\text { enhanced care model }\end{array}$ & Community trust & 129.00 \\
\hline Outpatient visit & $t$ & 63.00 \\
\hline Day case procedure & Acute trust & 231.00 \\
\hline $\begin{array}{l}\text { Outpatient physiotherapy (20 } \\
\text { min) }\end{array}$ & $t$ & 9.66 \\
\hline Inpatient physiotherapy (20 min) & $\dagger$ & 10.33 \\
\hline \multicolumn{3}{|l|}{ Contact with general practitioner: } \\
\hline In surgery & $\dagger$ & 13.00 \\
\hline At home & $\dagger$ & 39.00 \\
\hline \multicolumn{3}{|l|}{ Community nurse contact: } \\
\hline In surgery & $\dagger$ & 7.58 \\
\hline At home & $\dagger$ & 15.00 \\
\hline Primary care contact by phone & $\dagger$ & 15.00 \\
\hline Residential care per week & $\dagger$ & 247.00 \\
\hline Nursing home per week & $t$ & 370.00 \\
\hline
\end{tabular}

\section{$£ 1(\$ 1.9 ; € 1.5)$.}

*Resources embedded in cost per occupied bed day were nursing, medical, occupational therapy, pathology, drugs, capital charges, and overheads. †Netten and Dennett 1999. ${ }^{10}$

\section{Analysis}

Although our study was not planned as an equivalence trial, given the evidence of the clinical trial ${ }^{7}$ we have assumed no clinical gains from the nurse led unit. We therefore carried out a cost minimisation analysis. To calculate costs per category of resource use we multiplied utilisation data by unit costs, then aggregated the result to produce total costs for period 1, period 2, and total costs for the six month study period. We produced summary statistics for each cost variable (means, medians, and standard deviations). Two sample $t$ tests were used to compare mean costs between the nurse led group and standard care group, with 95\% confidence intervals. Groups were also compared using a regression model controlling for referring ward and sex, as in the analysis of the primary outcomes. ${ }^{7}$ Results of the two analyses were virtually identical. Regression analyses are not reported here.

For our sensitivity analyses we focused on inpatient and total costs-that is, from the perspective of secondary care-because this was the only area in which costs differed between the groups. Comparisons were drawn in the same way as with other cost estimates. The sensitivity analyses were carried out to test the effect of varying the cost per occupied bed day for the nurse led unit, as this was the cost with the highest leverage and also the estimate most vulnerable to questions about accuracy. We recalculated inpatient costs during period 1 and period 2 and total costs for the study period, according to the following assumptions, which are based on reasonable variability observed between wards within the directorate: nurse led unit cost per occupied bed day $15 \%$ lower (£213.08); nurse led unit cost per occupied bed day 20\% lower (£200.54); and nurse led unit cost per occupied bed day $25 \%$ lower (£188.01). These values are higher than the mean for acute general medical wards (£146.19, or $42 \%$ lower than the nurse led unit cost per occupied bed day), but this is consistent with the higher grade of nursing staff used 
Table 2 Major use of resources during nurse led care or standard care of post-acute medical patients. Values are means (medians)

\begin{tabular}{|c|c|c|}
\hline Resource & $\begin{array}{l}\text { Nurse led care group } \\
\qquad(\mathrm{n}=117)\end{array}$ & $\begin{array}{l}\text { Standard care group } \\
(\mathrm{n}=121)\end{array}$ \\
\hline \multicolumn{3}{|c|}{ Length of hospital stay (days) } \\
\hline \multicolumn{3}{|c|}{ Period 1 (until first discharge home): } \\
\hline Acute trust & $32.2(26)$ & $18.2(11)$ \\
\hline Community hospital & $0.8(0)$ & $8.3(0)$ \\
\hline Other & $0.4(0)$ & $2.5(0)$ \\
\hline Total period 1 & $33.4(27)$ & $28.9(18)$ \\
\hline Period 2 (readmissions) & $7.7(0)$ & $10.6(0)$ \\
\hline Total for periods 1 and 2 & 41.1 (32) & $39.5(31)$ \\
\hline \multicolumn{3}{|l|}{ Physiotherapy (20 min) } \\
\hline \multicolumn{3}{|l|}{ Inpatient: } \\
\hline Period 1 & $5.08(0)$ & $5.88(0)$ \\
\hline Period 2 & $0.03(0)$ & $1.07(0)$ \\
\hline Community & $0.03(0)$ & $0.36(0)$ \\
\hline \multicolumn{3}{|c|}{ Contacts with general practitioner } \\
\hline In surgery & $1.70(0.5)$ & $1.90(0.5)$ \\
\hline At home & $2.76(1)$ & $2.53(1.5)$ \\
\hline By phone & $0.44(0)$ & $0.61(0)$ \\
\hline \multicolumn{3}{|c|}{ Contacts with community nurse } \\
\hline In surgery & $0.03(0)$ & $0.51(0)$ \\
\hline At home & $4.24(0)$ & $4.94(0)$ \\
\hline
\end{tabular}

by the nurse led unit. Cost reductions of $15 \%, 20 \%$, and $25 \%$ equate to reductions in length of stay of $5,6.4$, and 8 days, respectively.

The fourth assumption, that nurse led unit cost per occupied bed day was equivalent to the cost of a general practitioner led community hospital $(60 \%$ lower, $£ 100.50)$, allowed comparison with the least expensive feasible alternative to care in a nurse led unit. If the direction of results does not change under these assumptions, then the findings can be taken as robust.

\section{Results}

In total, 240 post-acute medical patients were randomised to receive either care in a nurse led unit or standard post-acute care. Two refused data collection for the economic evaluation. Outcomes and resource use were measured at six months and, as there were no significant differences in primary outcomes, we carried out a cost minimisation analysis. Table 1 details the costs of resources. Most comparisons were not statistically significant, although there were some important exceptions (tables 2-5). In period 1, medical directorate costs for the nurse led care group were $£ 1920$ lower on average than those for the standard care group, as expected (see table 3 ). In addition, community hospital costs for patients in the nurse led unit were $£ 1013$ lower on average. During the same period, however, the costs within the nurse led care group were $£ 6560$ higher on average, resulting in overall inpatient costs during period 1 that were $£ 3082$ higher. With the exception of a decrease in other acute ward costs for the nurse led care group, we found no significant differences in costs during period 2 (see table 4 ).

Total costs for the six month study period were significantly greater in the nurse led care group (see table 5), with a difference in means of $£ 2710$. Hospital costs after discharge were similar between the two groups, with the cost difference being accounted for by longer length of stay and higher bed day costs in the nurse led unit in period 1.

Our sensitivity analyses focused on the cost per occupied bed day, given that the major cost drivers were cost per bed day and overall length of hospital stay in an acute ward (table 6). The
Table 3 Costs from randomisation to discharge home (period 1) for nurse led care or standard care of post-acute medical patients

\begin{tabular}{|c|c|c|c|}
\hline \multirow[b]{2}{*}{ Resource item } & \multicolumn{2}{|c|}{ Mean (median) cost $(£)^{\star}$} & \multirow[b]{2}{*}{$\begin{array}{l}\text { Difference in means } \\
(95 \% \mathrm{Cl})\end{array}$} \\
\hline & $\begin{array}{l}\text { Nurse led care } \\
\text { group }(n=117)\end{array}$ & $\begin{array}{l}\text { Standard care } \\
\text { group }(n=121)\end{array}$ & \\
\hline \multicolumn{4}{|l|}{ Acute hospital: } \\
\hline General medical ward & 602 (146) & 2502 (1462) & $-1920(-2486$ to -1314$)$ \\
\hline Nurse led unit & $6560(5264)$ & $0(0)$ & 6560 (5429 to 7692) \\
\hline Other acute wards & $626(0)$ & $1192(0)$ & $-566(-2014$ to 883$)$ \\
\hline Community hospital & $102(0)$ & $1116(0)$ & $-1013(-1573$ to -453$)$ \\
\hline $\begin{array}{l}\text { Total period } 1 \text { inpatient } \\
\text { care }\end{array}$ & $7892(6100)$ & 4810 (2631) & 3082 (1161 to 5002) \\
\hline
\end{tabular}

mean difference in total costs remained higher for the nurse led unit under the first three assumptions, although these differences were not significant. At no point, even when the least expensive community hospital rate was assumed, did care in a nurse led unit become significantly less expensive than standard care in hospital.

\section{Discussion}

Both inpatient costs and total costs were significantly higher for nurse led inpatient care compared with standard care of medical patients on an acute ward. This finding holds true whether the acute trust perspective or wider NHS perspective is taken and in a range of cost estimate situations. The only cost saving was a reduction in the costs associated with using a community hospital. Conventionally, when a trial produces no significant

Table 4 Readmission (period 2) costs associated with nurse led care or standard care of post-acute medical patients

\begin{tabular}{|c|c|c|c|}
\hline \multirow[b]{2}{*}{ Resource item } & \multicolumn{2}{|c|}{ Mean cost $(\mathfrak{E})^{\star}$} & \multirow[b]{2}{*}{ Difference $(95 \% \mathrm{Cl})$} \\
\hline & $\begin{array}{l}\text { Nurse led care } \\
\text { group }(n=117)\end{array}$ & $\begin{array}{l}\text { Standard care } \\
\text { group }(n=121)\end{array}$ & \\
\hline \multicolumn{4}{|l|}{ Acute hospital: } \\
\hline General medical ward & 604 & 500 & 103 (-286 to 493$)$ \\
\hline Nurse led unit & 296 & 64 & 231 (-161 to 624$)$ \\
\hline Other acute wards & 390 & 1184 & $-794(-1531$ to -57$)$ \\
\hline Community hospital & 155 & 131 & 24 (-224 to 272) \\
\hline Total costs for period 2 & 1444 & 1879 & $-435(-1406$ to 536$)$ \\
\hline
\end{tabular}

$£ 1(\$ 1.9 ; € 1.5)$.

${ }^{*}$ Costs rounded to nearest pound.

Table 5 Total costs during six month follow-up for nurse led care or standard care of post-acute medical patients

\begin{tabular}{|c|c|c|c|}
\hline \multirow[b]{2}{*}{ Resource item } & \multicolumn{2}{|c|}{ Mean (median) cost $(£)^{*}$} & \multirow[b]{2}{*}{$\begin{array}{c}\text { Difference in means } \\
(95 \% \mathrm{Cl})\end{array}$} \\
\hline & $\begin{array}{l}\text { Nurse led care } \\
\text { group }(n=117)\end{array}$ & $\begin{array}{l}\text { Standard care } \\
\text { group }(n=121)\end{array}$ & \\
\hline $\begin{array}{r}\text { Period } 1 \text { (until first } \\
\text { discharge home) } \\
\end{array}$ & $7892(6100)$ & 4810 (2631) & 3082 (1161 to 5002) \\
\hline Period 2 (readmissions) & $1444(0)$ & $1879(0)$ & $-435(-1406$ to 536$)$ \\
\hline Physiotherapy & $59(10)$ & $83(21)$ & -25 (-69 to 20) \\
\hline Radiology & $24(0)$ & $18(0)$ & $6(-17$ to 29$)$ \\
\hline $\begin{array}{l}\text { Accident and } \\
\text { emergency } \\
\text { department }\end{array}$ & $22(0)$ & $14(0)$ & 7 (-5 to 20$)$ \\
\hline Outpatient and day case & $84(53)$ & $75(0)$ & 8 (-27 to 43) \\
\hline $\begin{array}{l}\text { Primary care and } \\
\text { community care }\end{array}$ & $168(82)$ & $137(65)$ & 31 ( -27 to 91$)$ \\
\hline Long term care (new) & $860(0)$ & $820(0)$ & 39 (-493 to 572$)$ \\
\hline $\begin{array}{l}\text { Total costs at six } \\
\text { months }\end{array}$ & $10529(7563)$ & 7819 (5184) & 2710 (518 to 4903 ) \\
\hline
\end{tabular}

$£ 1(\$ 1.9 ; € 1.5)$.

${ }^{\star}$ Costs rounded to nearest pound. 
Table 6 Sensitivity analyses comparing costs for nurse led inpatient care and standard care of post-acute medical patients

\begin{tabular}{|c|c|c|c|}
\hline \multirow[b]{2}{*}{$\begin{array}{l}\text { Cost assumption for } \\
\text { inpatient period }\end{array}$} & \multicolumn{2}{|c|}{ Mean (median) cost $(£)^{*}$} & \multirow[b]{2}{*}{$\begin{array}{c}\text { Differences in means } \\
(95 \% \mathrm{Cl})\end{array}$} \\
\hline & $\begin{array}{l}\text { Nurse led care } \\
\text { group }(n=117)\end{array}$ & $\begin{array}{l}\text { Standard care } \\
\text { group }(n=121)\end{array}$ & \\
\hline \multicolumn{4}{|c|}{$\begin{array}{l}\text { Nurse led unit costs per } \\
\text { occupied bed day } \\
\text { ( } 15 \% \text { lower): }\end{array}$} \\
\hline Period 1 & 6908 (5273) & 4810 (2631) & 2098 (266 to 3930) \\
\hline Period 2 & $1399(0)$ & $1870(0)$ & -470 (-1416 to 476) \\
\hline Total & 9525 (6817) & 7827 (5184) & 1698 (-407 to 3804) \\
\hline \multicolumn{4}{|c|}{$\begin{array}{l}\text { Nurse led unit costs per } \\
\text { occupied bed day } \\
\text { (20\% lower): }\end{array}$} \\
\hline Period 1 & 6580 (4997) & 4810 (2631) & 1770 (-36 to 3575) \\
\hline Period 2 & $1385(0)$ & $1866(0)$ & $-481 \quad(-1420$ to 457$)$ \\
\hline Total & $9182(6675)$ & 7824 (5184) & 1359 (-718 to 3435$)$ \\
\hline \multicolumn{4}{|c|}{$\begin{array}{l}\text { Nurse led unit costs per } \\
\text { occupied bed day } \\
\text { ( } 25 \% \text { lower): }\end{array}$} \\
\hline Period 1 & 6252 (4721) & 4810 (2631) & 1441 (-338 to 3221) \\
\hline Period 2 & $1370(0)$ & $1863(0)$ & -493 (-1425 to 439) \\
\hline Total & 8839 (6633) & $7820(5184)$ & 1094 (-1031 to 3069) \\
\hline \multicolumn{4}{|c|}{$\begin{array}{l}\text { Nurse led unit costs per } \\
\text { occupied bed day } \\
\text { equivalent to general } \\
\text { practitioner led care in } \\
\text { community hospital } \\
\text { (60\% lower) }\end{array}$} \\
\hline Period 1 & 3961 & 4810 (2631) & -849 (-2495 to 798$)$ \\
\hline Period 2 & 1267 & 1841 & $-574(-1466$ to 318$)$ \\
\hline Total & 6446 & 7798 & $-1352(-3255$ to 551$)$ \\
\hline
\end{tabular}

$£ 1(\$ 1.9 ; € 1.5)$

${ }^{*}$ Costs rounded to nearest pound.

differences between treatment and control outcomes, the option with the lower cost should be the preferred choice. In this case, the nurse led model of care should not be pursued.

As with other evaluations of this type, it was difficult for us to obtain detailed cost breakdowns for hospital resources inputs. ${ }^{11}$ Differences in estimates from different sources within the trust raised concerns over the accuracy of costs attributed to the nurse led unit and to the acute wards, which seemed higher than anticipated in both cases, although not unreasonable. The evaluation was strengthened by the inclusion of costs for community care and residential care. Prospective, bottom-up data collection would have been preferable, but would have severely restricted the feasible sample size, reducing power without necessarily removing the need to make large assumptions in cost estimates. Instead, sensitivity analyses helped overcome the potential problem of inaccurate estimations or unusual costs; the analyses presented include values similar to the lower costs reported in the only other study that reports on costs for this model of care. ${ }^{9}$

Sensitivity analyses showed a clear trend for higher costs with nurse led care, although the differences were not significant; at no point did the nurse led option become significantly less expensive than standard care. Even assuming that the nurse led unit could reduce costs by as much as $25 \%$, the equivalent of reducing length of stay by eight days on average, treatment costs would not be lower than those from standard care. Cost implications are not, however, the only guide to practice in the NHS. The continued growth of this model of care suggests that acute trusts are willing to pay more to maintain an intermediate care option under their own management control, perhaps especially during periods of high demand for beds. When making decisions on the development of nurse led intermediate care it is necessary to consider whether costs for indirect care are apportioned fairly; where the medical directorate fits in the larger context of

\section{What is already known on this topic}

Nurse intermediate led care for post-acute medical patients is becoming increasingly popular

Such care does not seem to improve patient outcomes, raising the question of whether the model of care is cost effective

\section{What this study adds}

Costs for acute trusts and total costs are higher with nurse led intermediate care, even under generous assumptions about cost reductions

Investment in intermediate care in community hospital rather than acute hospital settings may be more cost effective.

secondary care; what the opportunity costs are of the resources (for example, space or staff) used in the model's implementation; and the effects of economies of scale: as these units increase in size (as they have done locally since this evaluation), costs may decrease. Given that patient outcomes are satisfactory, and such units reduce pressure on acute beds, a certain overall increase in cost may be acceptable.

It is possible that the costs of the nurse led model could be reduced, not only by increasing bed numbers but by setting boundaries on maximum length of stay. Setting boundaries on hospital stay seems to be the one favoured by the UK government in its approach to intermediate care. ${ }^{12}$ However, costs or length of stay would have to be reduced substantially for nurse led inpatient care to be less expensive than standard care, and the changes we outline could have a negative effect on patient outcomes. Given that, in this evaluation at least, a part of the stay on a nurse led unit seems to be substituting for a period of stay in a community hospital, ${ }^{7}$ investment in intermediate care in the community hospital setting may be a more appropriate way forward for some trusts. Finally, increased efficiency might be possible through education of staff on the ideal model of care delivery. Currently a high grade (more expensive) mix of skill seems to substitute for such education, but without improving quality of nursing above that in standard care settings. ${ }^{14}{ }^{14}$ Training would require additional investment, but could prove cost effective if the mix of skills could be altered or outcomes improved in the nurse led unit. The decision, however, must also take into consideration the wider context of intermediate care; other models of care may be both feasible and more cost effective. $^{11}$

We thank for their cooperation the Southampton University Hospitals Trust; the participating general practitioners; the managers, clinicians, and patients involved with the nurse led unit; the finance, accounting, and information staff in the trust; and the support of the other members of the Southampton Nurse Led Unit Evaluation Team: J Bray, J Brooking, D Coulson, P Lees, J Pearce, K Postle, L Sheron, J Warr, and R Wiles.

Contributors: BW conceived and led the original inpatient trial and, with RMP, defined the trial protocol. AS obtained funding and conceived and led the comprehensive follow-up and economic evaluation. RMP contributed as statistician to the design and analysis of the study.JWB collected data and, with BW, AS, and RMP, assisted in analysis and interpretation. BW led the writing of the paper and is its guarantor. All authors were involved in critical revision.

Funding: Grant D/10/11.97 from the NHS Executive Research and Development Directorate South and West Region.

Competing interests: None declared.

Ethical approval: South and west local research ethics committee. 
1 Department of Health. Shaping the future NHS: long term planning for hospitals and related services. London: $\mathrm{DoH}, 2000$

2 Department of Health. National service framework for older people. London: DoH, 2001

Department of Health. The NHS plan. London: DoH, 2000.

Steiner A. Intermediate care: more than a nursing thing? Age Ageing 2001;30:433-5.

5 Pearson A, Punton S, Durant I. Nursing beds: an evaluation of the effects of therapeutic nursing. Harrow: Scutari, 1992.

6 Griffiths P, Evans A. Evaluating a nurse-led inpatient service: an interim report. London: King's Fund, 1995.

7 Steiner A, Walsh B, Pickering RM, Wiles R, Ward J, Brooking JI, et al. Therapeutic nursing or unblocking beds? A randomised controlled trial of a post-acute intermediate ing or unblocking beds? A randomise

8 Griffiths P, Wilson-Barnett J, Richardson G, Spilsbury K, Miller F, Harris R. The effectiveness of intermediate care in a nursing-led in-patient unit. Int J Nurs Stud 2000;37:153-61.

9 Griffiths P, Harris R, Richardson G, Hallett N, Heard S, Wilson-Barnett. Substitution of a nursing-led inpatient unit for acute services: randomized controlled trial of outcomes and cost of nursing-led intermediate care. Age Ageing 2001;30:483-8.

10 Netten A, Dennett J. Unit costs of community care, 3rd ed. Kent: Personal Social Services Research Unit, 1999

11 Coast J, Richards S, Peters T, Gunnell D, Darlow M, Pounsford J. Hospital at home or acute hospital care? A cost-minimisation analysis. BMJ 1998;316:1802-6.

2 Department of Health. Health service circular 2001/01: intermediate care. London: DoH, 2001.
13 Wiles R, Postle K, Steiner S, Walsh B. Nurse-led intermediate care: an opportunity to develop enhanced roles for nurses? J Adv Nurs 2001;34:813-21.

14 Walsh B, Steiner A, Warr J, Sheron L, Pickering R. Nurse-led inpatient care: opening the 'black box.' Int J Nurs Stud 2003;40:307-19.

(Accepted 8 February 2005)

doi $10.1136 /$ bmj. $38397.633588 .8 \mathrm{~F}$

School of Nursing and Midwifery, University of Southampton, Southampton SO17 1BJ

Bronagh Walsh lecturer

Department of Geriatric Medicine, University of Southampton Andrea Steiner senior lecturer

Medical Statistics Group, Health Care Research Unit, Southampton General Hospital, Southampton SO16 6YD

Ruth M Pickering senior lecturer

Elderly Care Research Unit, University Department of Geriatric Medicine, Southampton General Hospital

Jilly Ward-Basu research nurse

Correspondence to: B Walsh b.m.walsh@soton.ac.uk 